Bull. Mater. Sci., Vol. 8, No. 4, October 1986, pp. 497-503.

(C) Printed in India.

\title{
Thermal transformation in a chrysotile asbestos
}

\author{
A K DATTA, B K SAMANTARAY and S BHATTACHERJEE \\ Department of Physics, Indian Institute of Technology, Kharagpur 721 302, India
}

MS received 19 December 1985

\begin{abstract}
Structural changes accompanying thermal transformation in a chrysotile asbestos sample of Indian origin upto a temperature of $900^{\circ} \mathrm{C}$ have been investigated by $\mathrm{x}$-ray method. The changes in lattice parameters have been systematically measured by applying a least square refinement technique and the crystallite size and strain defects at different stages have been estimated by line profile analysis of the diffraction peaks. The present study also confirms the earlier results on stepwise transformation of chrysotile fibres. This sequence of transformation has been explained assuming two different types of crystallites as reported in kaolinite.
\end{abstract}

Keywords. Dehydration; transformation; chrysotile; asbestos; $x$-ray diffraction.

\section{Introduction}

Chrysotile asbestos is of great scientific interest and commercial value because of its complex structure and multiple uses. It belongs to the serpentine group of clay minerals with 1:1 layers which curl into cylindrical rolls. Its ideal formula per half unit cell is $\mathrm{Mg}_{3} \mathrm{Si}_{2} \mathrm{O}_{5}(\mathrm{OH})_{4}$ and is built up of alternate half layers of silicate and brucite (magnesium hydroxide). Misfit between the two half layers results in curvature with the longer brucite layer lying on the convex side. The curved layers form cylindrical fibrils with the $a$-axis along the fibre axis, $b$ along the circumference and $c$ along the radius of the fibres (Brindley and Brown 1980).

Several studies have been reported (Brindley and Zussman 1957; Glasser et al 1962; Martin 1977; Hey and Bannister 1948; Santos and Yada 1979) using different methods. These results show that chrysotile with the loss of structural water transforms into an anhydrous phase around $600^{\circ} \mathrm{C}$ followed by formation of forsterite. Finally above $810^{\circ} \mathrm{C}$ the anhydrous phase recrystallizes into enstatite. However, the exact nature of the entire sequence of this transformation mechanism is yet to be fully understood.

No attempt has so far been made to study this transformation by applying the technique of line profile analysis for estimating the extent of lattice defects which are likely to increase with temperature in this type of mineral with cylindrical structure. Systematic estimation of the crystallite size and strain defects which are present in this type of sample with curved structure as described earlier, in conjunction with accurate measurements of the changes of lattice parameters from the $x$-ray diffraction patterns at different temperatures may reveal several new information which might suggest a satisfactory model of the entire sequence of this transformation. The present work reports the results of studies carried out on a chrysotile sample of Indian origin following this approach. 


\section{Experimental methods}

\subsection{Chemical and differential thermal analysis}

A specimen of chrysotile from Cuddapah (India) was selected for the present investigation. The sample was silky fibrous in form and about 1 to $2 \mathrm{~cm}$ long. The average chemical composition of the sample is shown in table 1 . The result of the thermal analysis is shown in figure 1 . It consists of a strong and broad endothermal band with peak at about $660^{\circ} \mathrm{C}$ followed by a sharp exothermal peak at $814^{\circ} \mathrm{C}$, characteristic of chrysotile. The broad endothermal peak is, however, marked by a number of small humps resembling necks on either side of the peak corresponding to 595,715 and $753^{\circ} \mathrm{C}$ respectively. The finely powdered samples were heated below and above the DTA peak temperatures at 580,640,700,750,800 and $900^{\circ} \mathrm{C}$ respectively each for $5 \mathrm{hr}$.

Table 1. Chemical analysis of chrysotile sample at room temperature.

\begin{tabular}{lc}
\hline Component & Percentage \\
\hline $\mathrm{SiO}_{2}$ & 36.72 \\
$\mathrm{Al}_{2} \mathrm{O}_{3}$ & Trace \\
$\mathrm{Fe}_{2} \mathrm{O}_{3}$ & $2 \cdot 48$ \\
$\mathrm{FeO}$ & Trace \\
$\mathrm{TiO}_{2}$ & Trace \\
$\mathrm{MnO}$ & 0.04 \\
$\mathrm{CaO}$ & 1.50 \\
$\mathrm{MgO}$ & 40.10 \\
$\mathrm{Na}_{2} \mathrm{O}$ & 0.07 \\
$\mathrm{~K}_{2} \mathrm{O}$ & 0.04 \\
$\mathrm{H}_{2} \mathrm{O}$ & 18.53 \\
\hline
\end{tabular}

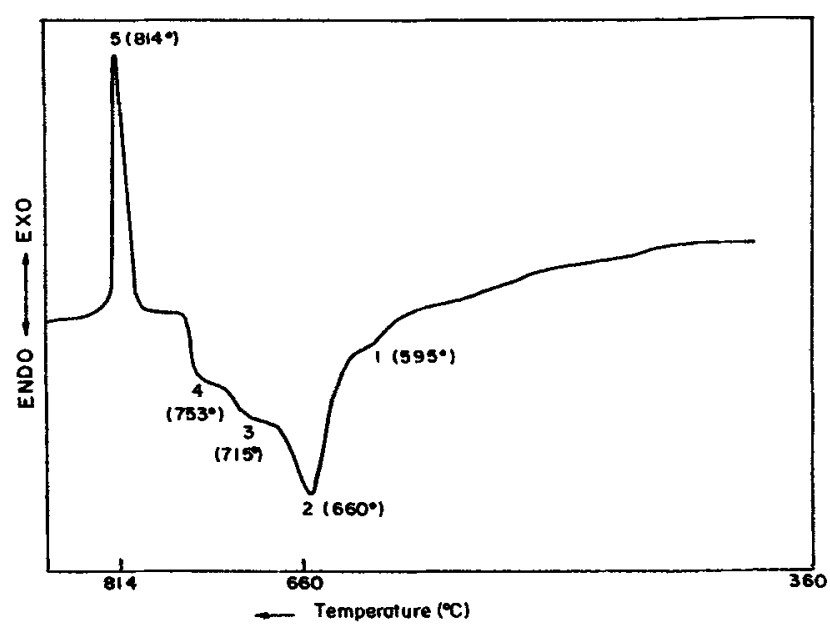

Figure 1. Differential thermal analysis curve of chrysotile. 


\section{$2.2 X$-ray diffraction analysis}

The sample preparation and the $\mathrm{x}$-ray diffraction techniques followed were similar to those described earlier (Mitra and Bhattacherjee 1969, 1970). X-ray Debye Scherrer powder photographs were taken and from the observed $d$-values, the changes in lattice parameters were studied by adopting Ito's (1949) method followed by a least square refinement using LAPOD programme (Langford and Marriner 1973).

Diffraction profiles of the samples were recorded in a Norelco $\mathrm{x}$-ray diffractometer at a scanning speed of $1 / 4^{\circ} / \mathrm{min}(2 \theta)$ using $\mathrm{CuK}_{\alpha}$ radiation. Crystallite size and microstrain were obtained from the variance of the corrected line profiles and using the relation (Mitra 1965)

$$
\frac{W \cos \theta}{\lambda \sigma}=\frac{1}{2 \pi^{2} P}+\frac{\lambda n^{2}}{\sigma \cos \theta} \frac{\left\langle e^{2}\right\rangle}{d^{2}}
$$

where $W$ is the variance in $(2 \theta)$ unit of the line profile, $P$ is the apparent crystallite size in the direction normal to the reflecting planes with interplanar spacing $d ; \sigma$ is the angular range of the profile; $\left\langle\mathrm{e}^{2}\right\rangle$ the mean square strain and $\theta$ the Bragg angle of reflection. Thus a plot of $W \cos \theta / \lambda \sigma$ against $\lambda n^{2} / \sigma \cos \theta d^{2}$ will be a straight line whose slope gives $\left\langle e^{2}\right\rangle$ and the intercept $P(=t / k)$ where $t$ is the true particle size and $k$ is the Scherrer constant.

The partially overlapped lines were resolved accurately by following the method of Mitra and Bhattacherjee (1970) and corrected for instrumental broadening by using the profiles of standard silicon sample. The values of crystallite size along the radial direction and the microstrain values were determined from the variance range plot of the (002), (004), (008) and (0010) reflections. The mean values of these parameters are shown in table 2 .

\section{Results and discussion}

The broad endothermal peak which extends between $568-768^{\circ} \mathrm{C}$ and marked by several small maxima clearly indicates that dehydration takes place in several steps. It is quite likely that there are different groups of particles affected at different stages. The sharp exothermal peak at $814^{\circ} \mathrm{C}$ indicates that rapid recrystallization occurs at this temperature. These results are in conformity with those of the previous workers as mentioned earlier. The $\mathrm{x}$-ray diffraction patterns of samples heated upto $580^{\circ} \mathrm{C}$

Table 2 Values of erystallite size and r.m.s. strain as obtained from variance analysis of (001) line profiles of chrysotile asbestos.

\begin{tabular}{ccc}
\hline $\begin{array}{c}\text { Temperature } \\
\left({ }^{\circ} \mathrm{C}\right)\end{array}$ & $\begin{array}{c}\text { Crystaflite size } \\
(\AA)\end{array}$ & $\begin{array}{c}\text { r.m.s. strain } \\
\left\langle e^{2}\right\rangle^{\mathbf{1 / 2}} \times 10^{3}\end{array}$ \\
\hline 30 & 425 & 1.894 \\
580 & 615 & 0.245 \\
640 & 705 & 0.653 \\
700 & 1010 & 0.334 \\
750 & 2850 & 0.733 \\
800 & 730 & 0.699 \\
900 & 625 & 0.698 \\
\hline
\end{tabular}


exhibited the usual lines, characteristic of chrysotile only. However, the patterns of samples at 640,700 and $750^{\circ} \mathrm{C}$ were marked by prominent peaks of forsterite also at $3 \cdot 88,3 \cdot 72,2 \cdot 77,2.81$ and $2.46 \AA$ in addition to the existing lines of chrysotile. On the other hand, diffraction patterns of the samples at 800 and $900^{\circ} \mathrm{C}$ contained, besides these peaks of foresterite and chrysotile, characteristic peaks of enstatite at 2.91, 2.55, $2.31 \AA$ respectively. These observations clearly indicate that chrysotile is converted to forsterite and enstatite in steps during this thermal transformation. During dehydration a part of chrysotile is converted to forsterite only, corresponding to the endothermal peak while partial conversion of chrysotile to both forsterite and enstatite takes place at higher temperatures which correspond to the exothermal region.

Table 3 shows the refined values of the lattice parameters of samples heated to different temperatures. Since prolonged heating even for $100 \mathrm{hr}$ at high temperatures does not fully convert chrysotile (Brindley and Hayami 1965), heating for $5 \mathrm{hr}$ in the present case converts only $40 \%$ at $800^{\circ} \mathrm{C}$. Hence quite justifiably, the lattice parameters measured from the patterns of samples at higher temperatures and shown in table 2, are considered to be that of the unaffected chrysotile. The room temperature data clearly demonstrate the monoclinic symmetry of the present sample. Table 2 shows that the $a$-values initially decrease systematically up to $640^{\circ} \mathrm{C}$ and thereafter increase gradually till $900^{\circ} \mathrm{C}$. The $b$-values also follow the same pattern of variation. On the other hand $c$-values increase steadily till $750^{\circ} \mathrm{C}$ beyond which they decrease slowly up to $900^{\circ} \mathrm{C}$. However, the $b$-values do not follow any systematic variation. Thus the temperature variation of lattice parameters in general shows a contraction along the axial $a$-direction up to $640^{\circ} \mathrm{C}$ accompanied by an expansion in the radial $c$-direction up to $750^{\circ} \mathrm{C}$. Contraction of the lattice in general and along the fibre axis, in particular, has been observed in fibrous chain silicate clay minerals (Bhattacherjee and Lokanatha 1984). Hence the present results are on expected lines.

On heating cavities possibly open up (Martin 1977) resulting in decrease of curvature of the rolled layers. This may lead to an extension of $c$ along the radial direction with release of strain and subsequent increase in crystallite size upto $750^{\circ} \mathrm{C}$ as shown in table 3 . The curvature along the surface is likely to change nonuniformly resulting in irregular variation of $b$ with dehydration and perhaps is responsible for the slight increase of $a$-values above $640^{\circ} \mathrm{C}$. It may be noted here that this process relates only to chrysotile sample and its dehydration products as the measurements are on the pattern of chrysotile only. After completion of dehydration above $750^{\circ} \mathrm{C}$,

Table 3. Variation of lattice parameters of chrysotile with temperature.

\begin{tabular}{rcccc}
\hline $\begin{array}{c}\text { Temperature } \\
\left({ }^{\circ} \mathrm{C}\right)\end{array}$ & $a(\AA)$ & $b(\AA)$ & $c(\AA)$ & $\beta(\mathrm{deg})$ \\
\hline 30 & $5 \cdot 4158$ & $9 \cdot 1959$ & $14 \cdot 5424$ & $95 \cdot 46$ \\
580 & $5 \cdot 3529$ & $9 \cdot 1610$ & $14 \cdot 8328$ & $90 \cdot 62$ \\
640 & $5 \cdot 3433$ & $9 \cdot 4868$ & $14 \cdot 8435$ & $89 \cdot 88$ \\
700 & 5.3667 & $9 \cdot 5028$ & $15 \cdot 0812$ & $90 \cdot 47$ \\
750 & $5 \cdot 3736$ & $9 \cdot 5146$ & $15 \cdot 1236$ & $92 \cdot 10$ \\
800 & $5 \cdot 3927$ & $9 \cdot 4628$ & $15 \cdot 0560$ & $95 \cdot 39$ \\
900 & $5 \cdot 4022$ & $9 \cdot 5318$ & 14.9318 & $96 \cdot 12$ \\
\hline
\end{tabular}


the process proceeds at a faster rate due to mutual migration of $\mathrm{Mg}$ and $\mathrm{Si}$ ions leading to the conversion of greater proportion of chrysotile to forsterite and enstatite. The straightening of the lattice probably causes slight decrease of $c$-values and increase of $a$-values. However, these points need further convincing explanation which is not possible at the present state of our knowledge.

A possible alternative explanation of the gradual transformation of the chrysotile sample into forsterite and enstatite in various steps can be given by assuming the existence of two types of crystallites, namely type I and type II, type I being more prone to dehydration than II as reported in kaolinite (Mitra and Bhattacherjee 1969). At lower temperatures only crystallites of type I get dehydrated and as temperature increases, more and more of type II get affected, while the already affected type I crystallites get converted into forsterite. The reaction rate increases above $800^{\circ} \mathrm{C}$ and conversion to enstatite also starts. This process will continue unabated even beyond $900^{\circ} \mathrm{C}$ till the conversion is complete.

The electron micrographs of the samples clearly reveal the usual cylindrical form of the fibres. Measurements of the length and width of the fibrils from the micrographs show that the average length is of the order of $20,000 \AA$ whereas the breadth is about $2000 \AA$. Dimensions of the fibrils are not changed appreciably at the initial stage of heating. However at very high temperatures $\left(900^{\circ} \mathrm{C}\right)$ the fibres collapse and take the form of lumps possibly due to the formation of forsterite and enstatite. Two representative micrographs of the samples, one at room temperature and the other at $900^{\circ} \mathrm{C}$ (at magnification 50,000 ) have been shown in figures $2 \mathrm{a}, \mathrm{b}$ to illustrate these characteristics.

The values of the crystallite size giving the thickness of the layers along the radial $c$-direction and the corresponding microstrain as calculated from the variance analysis of the 001 reflections are shown in table 3 . It is seen that the crystallite size increases rapidly from about $400 \AA$ at room temperature to $2800 \AA$ at $750^{\circ} \mathrm{C}$ beyond which the size falls sharply. The corresponding strain values show a gradual decrease till $700^{\circ} \mathrm{C}$ and thereafter statistically remain more or less the same upto $900^{\circ} \mathrm{C}$. Since the diffraction peaks of forsterite were too small to be accurately measured for variance-range analysis, a rough estimate of the crystallite size has been made from the integral width of the peaks. It has been observed that the crystallite size of forsterite remains almost the same at about $400 \AA$ in the temperature range 640 $750^{\circ} \mathrm{C}$ which corresponds to the endothermal peak in the DTA. Thereafter the size rises sharply in two successive jumps to 700 and $1000 \AA$ at 800 and $900^{\circ} \mathrm{C}$ respectively. It can be inferred from these data that there is sharp increase of crystallite size accompanied by decrease of microstrain of the forsterite product above $750^{\circ} \mathrm{C}$ which marks the end of dehydration and the beginning of recrystallization as shown by DTA. The rapid growth may be attributed to annealing effect at such high temperature. The rapid fall in crystallite size of chrysotile accompanied by increase of size of forsterite above $750^{\circ} \mathrm{C}$ is indicative of conversion to forsterite at a faster rate and larger proportion above $750^{\circ} \mathrm{C}$. Also the rapid growth of size of the forsterite suggests that defects are removed from the converted forsterite in this temperature range.

As has been observed (Ball and Taylor 1961) and recently confirmed by several workers (Santos and Yada 1979; Martin 1977) the dehydration of chrysotile goes through several steps. In the first stage there is a removal of the hydroxyl ions, in the second stage there is a slow growth of forsterite because of $\mathrm{SiO}_{2}$ rich regions 

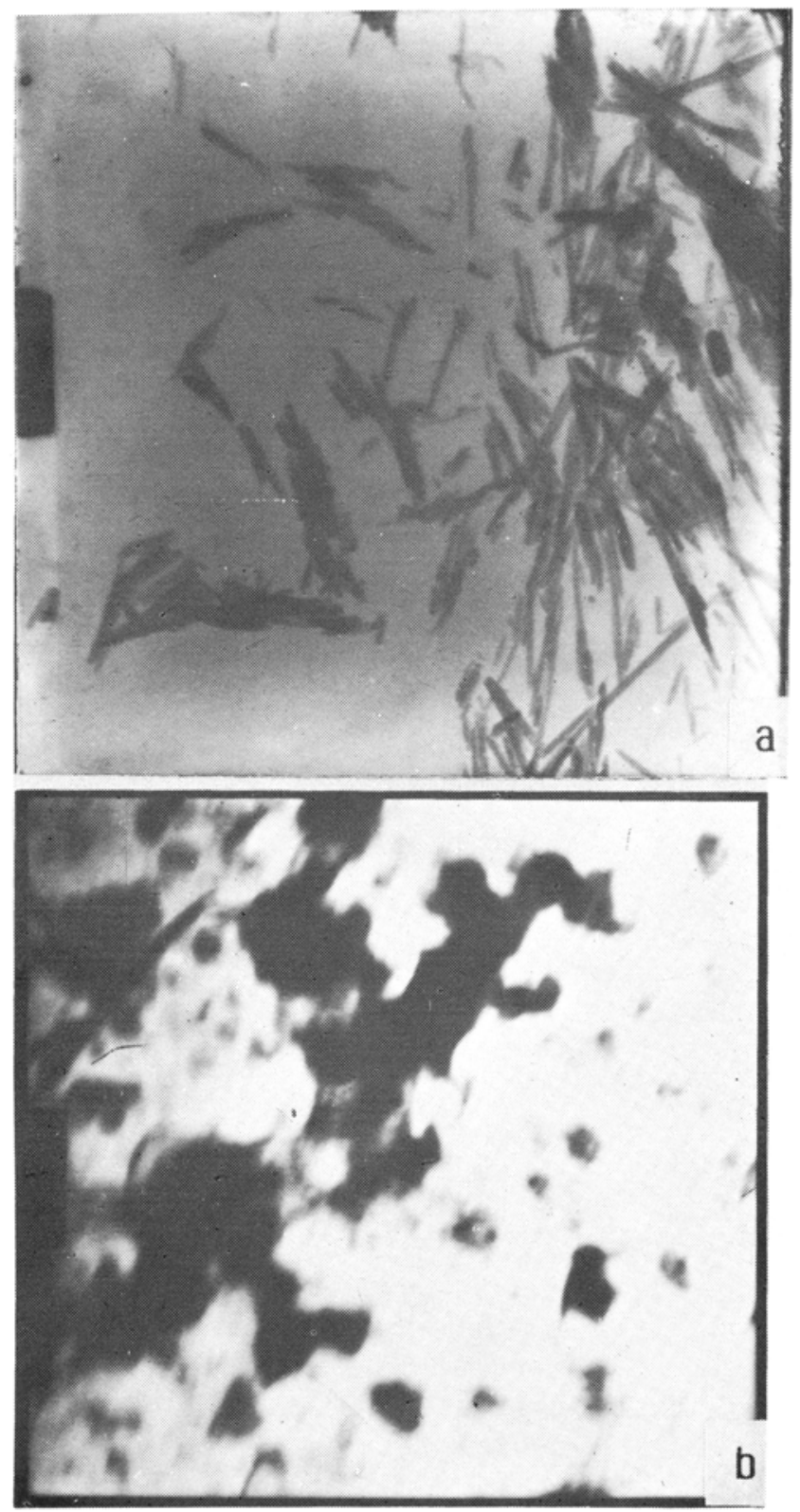

Figure 2. Transmission electronmicrographs of chrysotile sample at different temperatures (a) $30^{\circ} \mathrm{C}$. (b) $900^{\circ} \mathrm{C}, \times 50,000$

inhibiting further recrystallization and a rapid formation of forsterite and enstatite through mutual migration of $\mathrm{Mg}$ and $\mathrm{Si}$ ions at high temperatures beyond $800^{\circ} \mathrm{C}$.

The present observations also confirm the stepwise transformations of the chrysotile fibres leading to the formation of forsterite and enstatite as discussed. However, the present study shows that in the first stage which extends upto about $640^{\circ} \mathrm{C}$ when dehydration starts with the expulsion of hydroxyl water, the lattice 
transforms rather slowly mainly due to the contributions of the first type of crystallites. At the next stage which extends upto 750 marking the completion of dehydration, slow conversion of the already affected crystallites of type I into forsterite starts while more of type II gets dehydrated with further lattice transformation accompanied by increase of crystallite size in the radial direction owing to release of strain consequent upon possible opening up of cavities in the curved layer as mentioned earlier. This process continues till $750^{\circ} \mathrm{C}$. In the final stage beyond $750^{\circ} \mathrm{C}$, rapid recrystallization of the already affected crystallites into forsterite and enstatite takes place with changes of a and $\mathrm{c}$ in reverse direction. Consequently the size of chrysotile reduces at the expense of development of more forsterite and enstatite as revealed by the gradual increase of forsterite and enstatite peaks. As the process continues more and more of type II crystallites are converted till the process is complete.

\section{References}

Ball M C and Taylor H F W 1961 Mineral. Mag. 32754

Bhattacherjee S and Lokanatha S 1984 Trans. Indian Ceram. Soc. 43149

Brindley G W and Brown G 1980 Crystal structure of clay minerals and their $x$-ray identification (London: Mineralogical Society) p 13

Brindley G W and Hayami R 1965 Mineral. Mag. 35189

Brindley G W and Zussman J 1957 Am. Mineral. 42461

Glasser L S D, Glasser F P and Taylor H F W 1962 Q. Rev. Chem. Soc. 16343

Hey M H and Bannister F A 1948 Mineral. Mag. 28333

Ito T 1949 Nature (London) 164755

Langford J I and Marriner G F 1973 Powder pattern programmes, Univ. of Birmingham, Dept. of Physics

Martin C J 1977 Mineral Mag. 41453

Mitra G B 1965 Acta Crystallogr. 18464

Mitra G B and Bhattacherjee S 1969 Am. Mineral 541409

Mitra G B and Bhattacherjee S 1970 Acta Crystallogr. B26 2124

Santos H D S and Yada K 1979 Clays Clay Miner. 27161 